\title{
Synthesis and Characterisation of Colorants Derived from 1,4-Diamino Anthraquinone Polyamides
}

\author{
Mohammad Sani Gumel ${ }^{1}$, Mohammed Kabir Yakubu ${ }^{2 *}$, Mansur Bala Ibrahim¹, Rakesh Kumar ${ }^{3}$ \\ ${ }^{1}$ Department of Pure and Industrial Chemistry, Bayero University, Kano, Nigeria \\ ${ }^{2}$ Department of Textile Science and Technology, Ahmadu Bello University, Zaria, Nigeria \\ ${ }^{3}$ Centre for Scientific and Industrial Research (CSIR), Materials Science and Manufacturing, Port Elizabeth, South Africa \\ Email: *koko80001@yahoo.com
}

Received December 13, 2011; revised January 18, 2012; accepted February 25, 2012

\begin{abstract}
In this study, the polycondensation products of a diamine anthraquinone (1,4-diamino anthraquinone) and some aliphatic diacids with different methylene numbers were synthesised. Their UV-visible spectroscopy and thermal properties were then characterised. The synthesis was achieved by reacting equimolar solutions of the amine and the acid halides. The structure and thermal properties of the products were characterised. FT-IR Spectra of all the three products revealed the formation of amide due to the presence of strong bands at 1565 and $3390 \mathrm{~cm}^{-1}$ assignable to $\mathrm{C}=\mathrm{O}$ stretching and N-H vibrations. Differential Scanning Calorimetry revealed high melting exotherms for the products. Thermogravimetry revealed moderate thermal stabilities for Poly NAM and Poly NAS and low thermal stability for Poly NAA which indicated $5.9 \%, 7.1 \%$ and $61.2 \%$ weight losses at $285^{\circ} \mathrm{C}, 285^{\circ} \mathrm{C}$ and $374^{\circ} \mathrm{C}$ for the three products respectively. The wavelengths of maximum absorbance for the dye samples are $601.5,591$ and $589 \mathrm{~nm}$ respectively with absorptivity coefficients $\left(a_{1 \mathrm{~cm}}^{1 \%}\right)$ of 11640000,11610000 and 11560000 respectively.
\end{abstract}

Keywords: Anthraquinone; Polymeric Dyes; Polyamide; Synthesis; Characterisation

\section{Introduction}

Study on the synthesis and application of polymeric dyes has aroused interest in recent years. Polymeric dyes due to the advantage of molecular size do not sublime, are nonabrasive, and generally have low toxicity [1]. They have been widely applied on fibres because of certain essential dye properties such as fast levelling, fastness to light and wet treatment, low sublimation rate, and very good thermal and chemical resistance [2,3]. Xu et al., [4] stated that polymeric dyes have excellent brightness and are extremely fadeless. They have been used in food coloration and surface coating of plastic objects, as hair dyes [5]; solid state laser dyes [6]; jet Printing [1,7].

Polymeric dyes constituting polyesters, polyurathanes and polystyrene have been reported several years ago [8-10]. Research activity in the area is still very active; polymeric dyes containing the anthraquinone structure and their application on polyethylene terephthalate [11] (Qinghua, 2002), synthesis and light emitting properties of polymeric metal complex dyes based on hydroxyquinoline moiety [12]; polymeric dyes for photovoltaic applications [13]; and synthesis of novel water soluble cross linked polymeric dye with good dyeing properties [14]. Others include the synthesis of coloured polyureas

\footnotetext{
${ }^{*}$ Corresponding author.
}

$[15,16]$, polyurethane derivatives polymeric dyes that have fluorescent properties have also been reported [17, $18]$.

The paper discusses the synthesis of polymeric dyes using low temperature solution polycondendensation technique and characterizing the products using FT-IR spectrophotometry, differential Scanning Calorimetry and Thermogravimetry. Attempt has been made to apply the dyes unto cotton fabric; a cellulosic material by leuco vatting method. This is the first attempt to do this as no literature source has hinted to this. The dyes were also applied to polyester materials by high pressure as disperse dyes.

\section{Experimental}

\subsection{Reagents}

Anthraquinone, 1,4-diamino, was purchased from Sigma Aldrich and was used without further purification. Malonic acid (BDH), Succinic acid (BDH), Adipic acid (BDH), thionyl chloride, ethanol, chloroform, petroleum ether, sodium hydroxide, DMF and methanol are reagent grade and were used without further purification.

\subsection{Instruments}

Melting points were determined with Gallenkamp melt- 
ing point apparatus, intrinsic viscosities were measured in ethanol using Ubelohde viscometer, CECIL CE 7400 model spectrophotometer was used for UV/Visible spectrometry, FT-IR spectra were obtained using Fourier Transformed Infra red (FT-IR) spectrometer (Perkin Elmer Model), DSC studies were conducted using Dupont 200 thermal analyser.

\subsection{Method for the Synthesis of Polymeric Dyes}

Anthraquinone, 1,4-diamino (0.01 M) was dissolved in $15 \mathrm{ml}$ of N,N-dimethylformamide in a $100 \mathrm{ml}$ onenecked flask. Diacid halide $(0.01 \mathrm{M})$ was added portion wise with stirring while the temperature was maintained at $15^{\circ} \mathrm{C}$ in an ice-cooled water bath for one hour. The solution was then poured into a blender cup containing $200 \mathrm{ml}$ water and vigorously blended to precipitate the polymer. The polymer was filtered, washed several times with water and dried in an oven at $100^{\circ} \mathrm{C}$ for 15 minutes [18-20].

\subsection{Methods for the Characterisation of the Polymeric Dyes}

\subsubsection{FT-IR Spectroscopy}

The samples were characterized using $\mathrm{KBr}$ disc sampling method. The disks were prepared by grinding the sample ( $2 \%$ by weight) in $\mathrm{KBr}$ which was then compressed into a disk and analyzed with the spectrophotometer. All the Spectra were recorded over the range $4000-400 \mathrm{~cm}^{-1}$. [21].

\subsubsection{UV/Visible Spectroscopy}

UV/Visible spectroscopic characterization was done with a CECIL CE 7400 Spectrophotometer. The samples were dissolved in ethanol to give a $0.01 \mathrm{~g} / \mathrm{dm}^{3}$ solution.

\subsubsection{Differential Scanning Calorimetry (DSC)}

A Dupont 200 thermal analyser was used to study the thermal properties of the polymeric dye samples in aluminium pans. The calorimeter was used with nitrogen as carrier gas, heating from $28^{\circ} \mathrm{C}$ to $308^{\circ} \mathrm{C}$ at a rate of $10^{\circ} \mathrm{C}$ per minute as described by previous workers $[22,23]$.

\subsubsection{Thermogravimetric Analysis (TGA)}

Thermogravimetric analysis (TGA) of approximately 200 $\mathrm{mg}$ dried samples was carried out at a heating rate of $10^{\circ} \mathrm{C} \cdot \mathrm{min}^{-1}$ from room temperature to $700^{\circ} \mathrm{C}$ under a nitrogen atmosphere on a TG-IR interface [24].

\subsection{Application of the Dyes}

\subsubsection{Dyeing of Cotton Piece}

A dye bath was prepared by dissolving $0.5 \mathrm{~g}$ of the powder in $5 \mathrm{ml}$ of ethanol and made $100 \mathrm{ml}$ with distil water.
To this dispersion, $5 \mathrm{ml}$ Caustic soda solution (10\%) and $0.1 \mathrm{~g}$ sodium dithionite were added. The solution was heated at $60^{\circ} \mathrm{C}$ until a clear solution was obtained. A cotton fabric, $0.5 \mathrm{~g}$ was then placed into the dyebath and dyeing carried out at $50{ }^{\circ} \mathrm{C}-60^{\circ} \mathrm{C}$ for about $45 \mathrm{~min}$. The fabric was then removed, squeezed without rinsing and allowed to stand in $10 \mathrm{~min}$ in the open air for oxidation. This is followed by rinsing in dilute acetic acid, hot water and then boiled in soap solution for $15 \mathrm{~min}$ and finally thoroughly rinsed in running tap and dried.

\subsubsection{Pressure Dyeing of Polyester}

A suspension of the dye was made involving $0.5 \mathrm{~g}$ of the dyes in ethanol and water as above and poured into a pressure cooker. A polyester fabric sample, $0.5 \mathrm{~g}$ was placed into the cooker and dyed for 1hour with continuous agitation. The sample was then removed, rinsed with detergent, water and then dried.

\subsubsection{Properties of the Dyed Samples}

Both fabric samples were tested for wash, light and rubbing fastness.

\section{Results and Discussion}

\subsection{Synthesis of the Polymeric Dyes}

The reaction between the diacid halides and the diamine anthraquinone leads to the polyamides according to Scheme 1, pale to bluish purple precipitates are produced. The aromatic diamine has low basicity due to the delocalization of the lone pairs on the amine groups leading to conjugation with the extended ring system. As a result of this its reactivity has to be catalysed by the addition of N,N-dimethylformamide which served both as a solvent and a proton acceptor. The percentage yields of the products being $63.4 \%, 61 \%$ and $54.5 \%$ for PolyNAM, PolyNAS and PolyNAA respectively contrasted significantly with the over $95 \%$ yield reported by Joshi et al., [16]; in the synthesis of coloured polyureas. Though the low reactivity of the aromatic diamines could account for these poor yields, some of the dyes could also have been lost during isolation of the products from the solvent system used.

\subsection{Characterization}

3.2.1. Structure Confirmation by FT-IR Spectroscopy The IR-spectra of the samples; summarized in Table $\mathbf{1}$ are identical in most respects; this is mainly because the polymers are homologues differing in the molecular formula of the repeat units by a $-\mathrm{CH}_{2-}$ [25]. They all show weak bands at $3387-3392 \mathrm{~cm}^{-1}$ due to the amide- $N-H$ stretching [26,27]. The peaks at $3263-3265$ $\mathrm{cm}^{-1}$ are attributable to $\mathrm{N}-\mathrm{H}$ absorptions of the end 


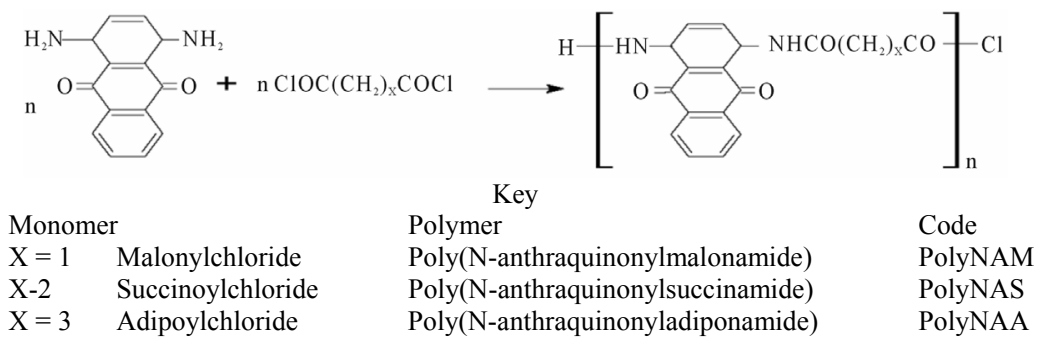

Scheme 1. Schematic illustration of the polymeric dye synthesis.

Table 1. Infra red absorption bands (Ibrahim, 2010).

\begin{tabular}{cccc}
\hline Group & $\begin{array}{c}\text { PolyNAM } \\
\mathrm{cm}^{-1}\end{array}$ & $\begin{array}{c}\text { PolyNAS } \\
\mathrm{cm}^{-1}\end{array}$ & $\begin{array}{c}\text { PolyNAA } \\
\mathrm{cm}^{-1}\end{array}$ \\
\hline N-H (Amide) & 3387 & 3392 & 3389 \\
N-H/NH & 3263 & 3265 & 3263 \\
C=O (Amides) & 1565 & 1566 & 1565 \\
C=O (Anthraquinone) & 1440 & 1440 & 1441 \\
& 1269 & 1270 & 1271 \\
& 1171 & 1172 & 1171 \\
C-N & 1021 & 1023 & 1025 \\
& 824 & 826 & 825 \\
& 718 & 721 & 721 \\
& 563 & 563 & 565 \\
\hline
\end{tabular}

groups. The peaks at $1565-1566 \mathrm{~cm}^{-1}$ are due to $\mathrm{C}=\mathrm{O}$ stretching of the amide linkage and the peak at $1440 \mathrm{~cm}^{-1}$ is ascribed to the anthraquinone $\mathrm{C}=\mathrm{O}$ absorption. These double bands are characteristic of amides [27-29]. The shift in the position of the absorption bands to lower frequencies could be due to the presence of H-bonding in the compounds [26].

\subsubsection{Melting Point of the Polymeric Dyes}

As seen in Table 2; all the three polymeric dye products are found to melt between $265^{\circ} \mathrm{C}-272^{\circ} \mathrm{C}$. The very close range of melting temperatures may be attributed to the similarity in their chemical structures. However, the little variations could be due to the variation in molar mass of the repeat units and the molecular mass of the polymers [27].

\subsubsection{Solubility of the Polymeric Dyes}

The solubility properties of the polymeric dyes are summarized in Table 3. The products are not soluble in most of the solvents used for the test. Solubility of the polymeric dyes in polar organic solvents could be attributed to the presence of polar N-H bond. The slight solubility in water is also attributable to hydrogen bonding between the amine/amide groups in the dye and hydroxyl groups in water [27].

\subsubsection{Viscosity of the Polymeric Dyes}

The viscosities of the polymeric dyes at $25^{\circ} \mathrm{C}$ are presented in Figure 1. The polymers indicated low intrinsic
Table 2. Melting points of the dye samples.

\begin{tabular}{cc}
\hline Sample & Melting point $\left({ }^{\circ} \mathbf{C}\right)$ \\
\hline PolyNAM & $267-272$ \\
PolyNAS & $265-267$ \\
PolyNAA & $266-270$ \\
\hline
\end{tabular}

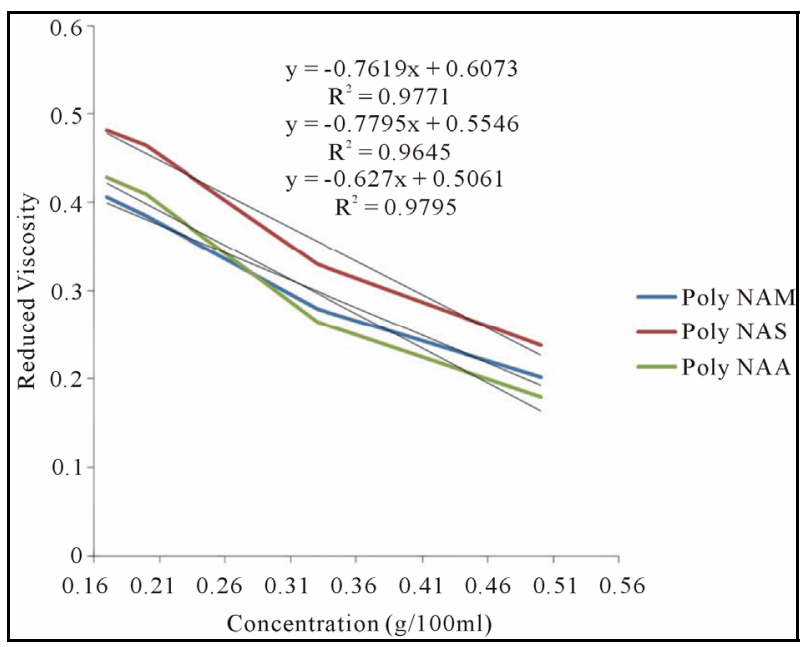

Figure 1. Plot of reduced viscosity against concentration.

viscosity which implies low molecular weight. By this property, the polymeric dyes will have a better ability of penetrating the fiber more than if the molecular weight were very high. The result agrees with the literature reported [11].

\subsubsection{UV/Visible Spectroscopy}

The analysis was carried out to determine the wavelength of maximum absorption $\left(\lambda_{\max }\right)$ for the polymeric dye samples. Results obtained are as shown in Table 4 and Figure 2.

The colour of the parent anthraquinone (1,4-diamino anthraquinone) was violet, with maximum absorption wavelength $\left(\lambda_{\max }\right)$ of $550 \mathrm{~nm}$. But after condensation, the colours of the polymeric dyes deepened to bluish violet all indicating bathochromic shifts of between $39-52 \mathrm{~nm}$. The absorptivity coefficients $\left(a_{1 \mathrm{~cm}}^{1 \%}\right)$ of the polymeric dyes were all extremely higher than that of the parent 
Table 3. Results of solubility test.

\begin{tabular}{cccccccccc}
\hline Sample & Ethanol & Methanol & Chloroform & Ether & Water & Acetone & $\mathrm{CCl}_{4}$ & Pet. Ether \\
\hline PolyNAM & $\mathrm{S}$ & $\mathrm{S}$ & $\mathrm{S}$ & $\mathrm{S}$ & $\mathrm{SS}$ & $\mathrm{S}$ & $\mathrm{I}$ & $\mathrm{SS}$ \\
PolyNAS & $\mathrm{S}$ & $\mathrm{S}$ & $\mathrm{S}$ & $\mathrm{S}$ & $\mathrm{SS}$ & $\mathrm{S}$ & $\mathrm{I}$ & $\mathrm{SS}$ \\
PolyNAA & $\mathrm{S}$ & $\mathrm{S}$ & $\mathrm{S}$ & $\mathrm{S}$ & $\mathrm{SS}$ & $\mathrm{S}$ & $\mathrm{I}$ & $\mathrm{SS}$ \\
\hline
\end{tabular}

$\mathrm{S}=$ soluble, $\mathrm{SS}=$ sparingly soluble and $\mathrm{I}=$ insoluble.

Table 4. $\lambda_{\max }$ Values for the dye samples.

\begin{tabular}{ccccc}
\hline Sample & $\lambda_{\max }(\mathrm{nm})$ & $\Delta \lambda_{\max }$ & Absorptivity coefficient $\left(\boldsymbol{a}_{1 \mathrm{~cm}}^{1 \%}\right) \times 10^{7}$ & $\Delta\left(\boldsymbol{a}_{1 \mathrm{~cm}}^{1 \%}\right) \times 10^{7}$ \\
\hline Parent anthraquinone & 550 & - & 0.026 & - \\
Poly NAM & 601.5 & +51.5 & 1.164 & 1.138 \\
Poly NAS & 591.0 & +41 & 1.161 & 1.135 \\
Poly NAA & 589.0 & +39 & 1.156 & 1.130 \\
\hline
\end{tabular}

Key: $\Delta \lambda_{\max }=\lambda_{\max }($ polymer $)-\lambda_{\max }\left(\right.$ anthraquinone), $\Delta\left(a_{1 \mathrm{~cm}}^{1 \%}\right)=a_{1 \mathrm{~cm}}^{1 \%}$ (polymer) $-a_{1 \mathrm{~cm}}^{1 \%}$ (anthraquinone).

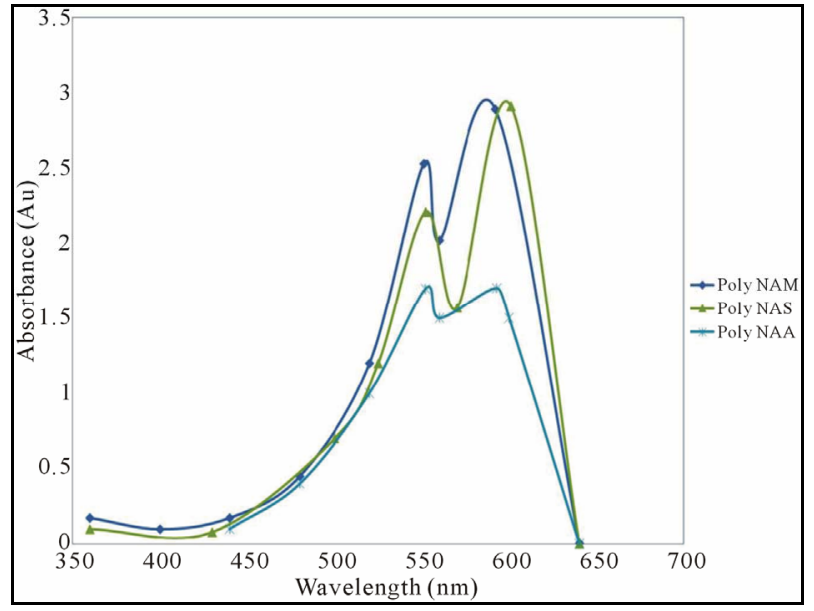

Figure 2. UV Visible Spectra of the polymeric dyes.

anthraquinone ie hyper chromic shifts of about $1.13 \times$ $10^{7}$. This result is consistent with an earlier work [30]. However both parameters suggested that the higher the molecular weight of the repeat unit the lower were the shifts.

\subsubsection{Differential Scanning Calorimetry}

Exothermic and Endothermic temperature values are presented in Table 5. Typical DSC spectra are presented on Figures 3-5. Differential Scanning Calorimetry (DSC) revealed a high melting exotherm at $270^{\circ} \mathrm{C}, 267^{\circ} \mathrm{C}$ and $269^{\circ} \mathrm{C}$ for PolyNAM, PolyNAS and PolyNAA respectively. The values are very close consistent with the basic structures of the monomers. PolyNAM and PolyNAS show $\mathrm{Tg}$ at $50^{\circ} \mathrm{C}$ and $55^{\circ} \mathrm{C}$ respectively. PolyNAA shows an endothermic peak at around $182^{\circ} \mathrm{C}$, this is considered the crystallization temperature. It is evident from the
DSC thermograms that only PolyNAA shows the ability to crystallize. This could be due to a number of factors such as average chain length, degree of polymerization, intermolecular forces of attraction etc. [28,31,32].

\subsubsection{Thermogravimetric Analysis}

The thermograms of the samples are indicated in Figures 6-8 and Table 6. Thermogravimetric analysis indicated that both polymers release some low molecular weight molecules probably water, at the peak temperatures of $60^{\circ} \mathrm{C}, 64^{\circ} \mathrm{C}$ and $85^{\circ} \mathrm{C}$ respectively for PolyNAM, PolyNAS and PolyNAA. In addition to the trend of increasing peak temperature with molecular weight of the diacids, the weight loss however decreased in the order $2.86 \%$, $1.67 \%$ and $1.28 \%$ respectively. PolyNAM and PolyNAS recorded weight losses of $5.9 \%$ (onset $123^{\circ} \mathrm{C}$ ) and $7.1 \%$ (onset $198^{\circ} \mathrm{C}$ ) respectively all with upper limit of $285^{\circ} \mathrm{C}$. PolyNAA which recorded a weight loss of $61 \%$ at $374^{\circ} \mathrm{C}$ indicated an onset of $229^{\circ} \mathrm{C}$. It is very clear that both Polymers have identical thermal stabilities loosing less than $10 \%$ of weight at $300^{\circ} \mathrm{C}$. The thermal stabilities of these polymers are however lower than Polyureas reported by Jauhari et al. [16].

No work seems to have been done on the application of carbonyl base polymeric dyes to cellulosic materials by vatting method. Majority of polymeric dyes synthesized are applied as disperse dyes to mostly hydrophobic substrates [33]. Some dyeing properties given in Table 7 showed that all the dyes have excellent washing and rubbing fastness on the two sample types and very good light fastness ratings. The excellent wash fastness recorded agreed with the findings of several workers [2, $30]$. 
Table 5. DSC endothermic/exothermic peaks for the dye samples.

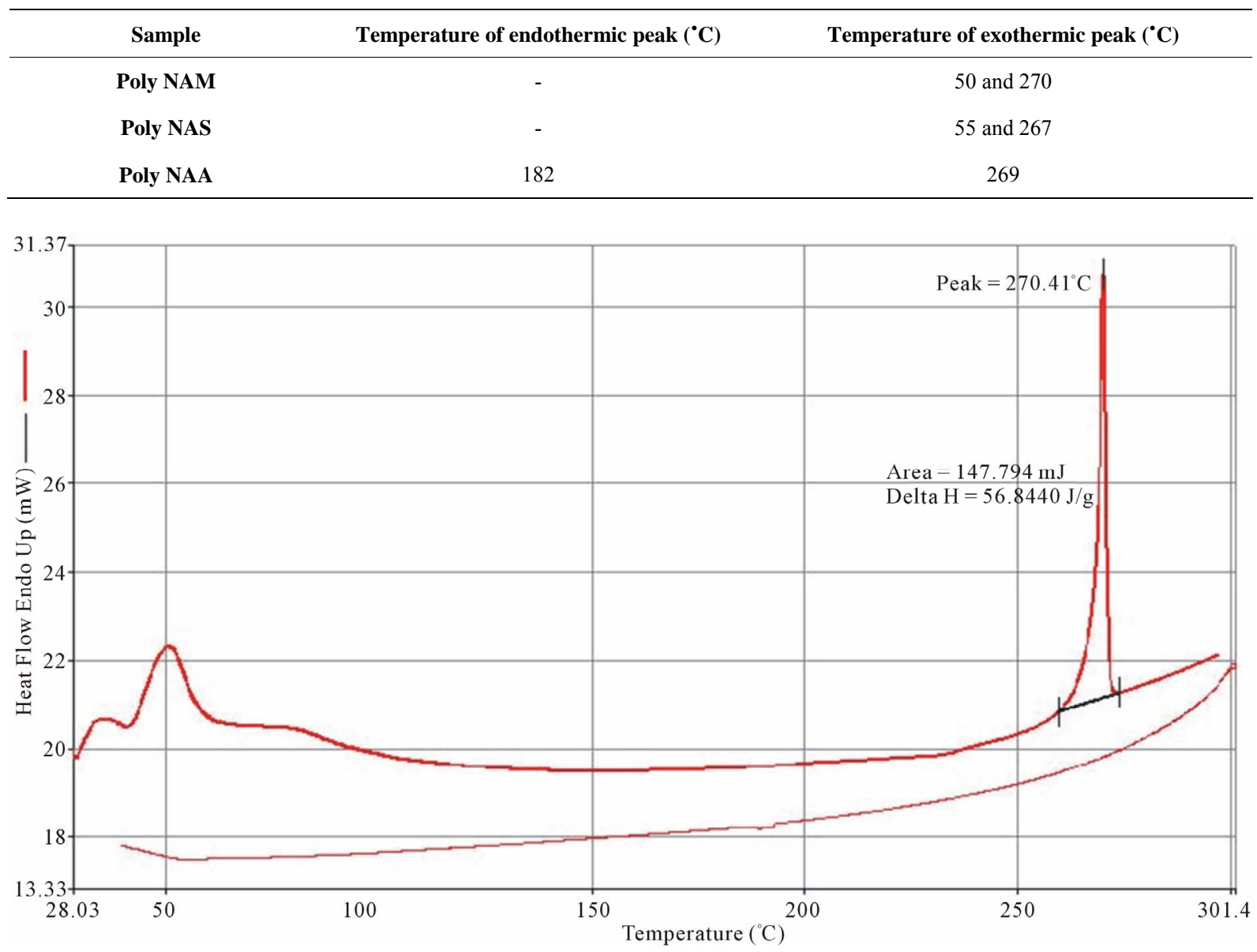

Figure 3. DSC thermogram of polyNAM.

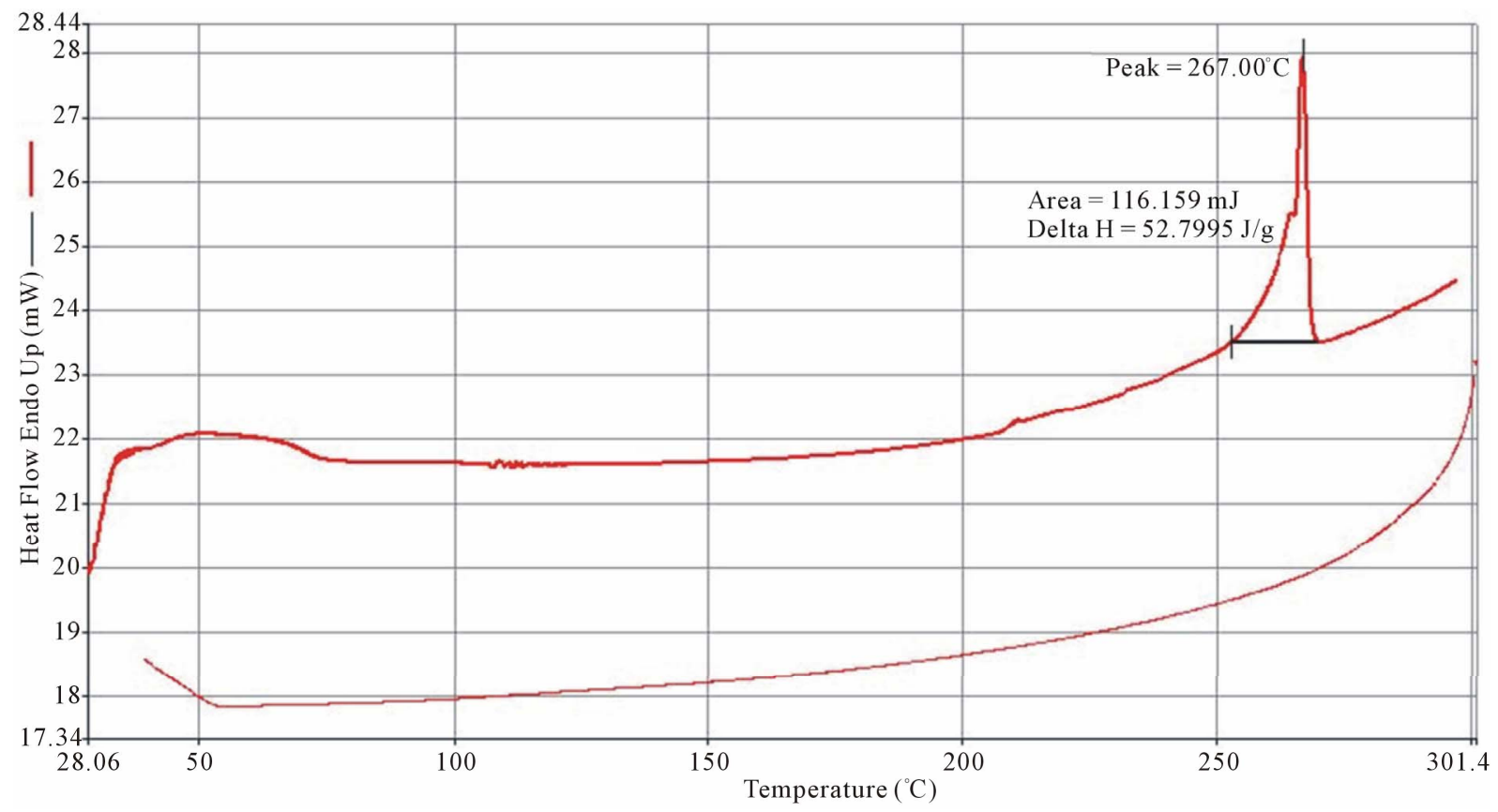

Figure 4. DSC thermogram of polyNAS. 


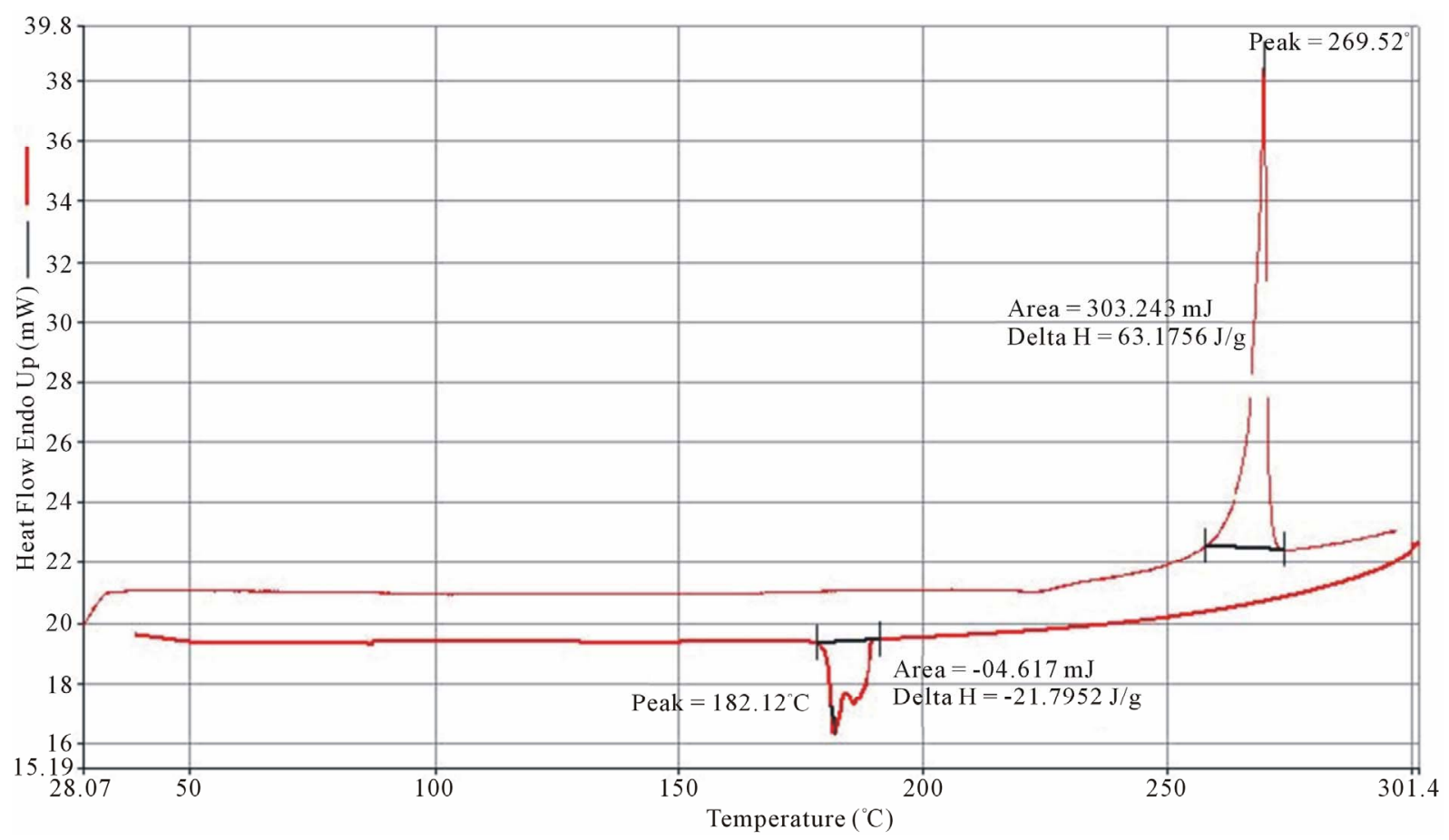

Figure 5. DSC thermogram of polyNAA.

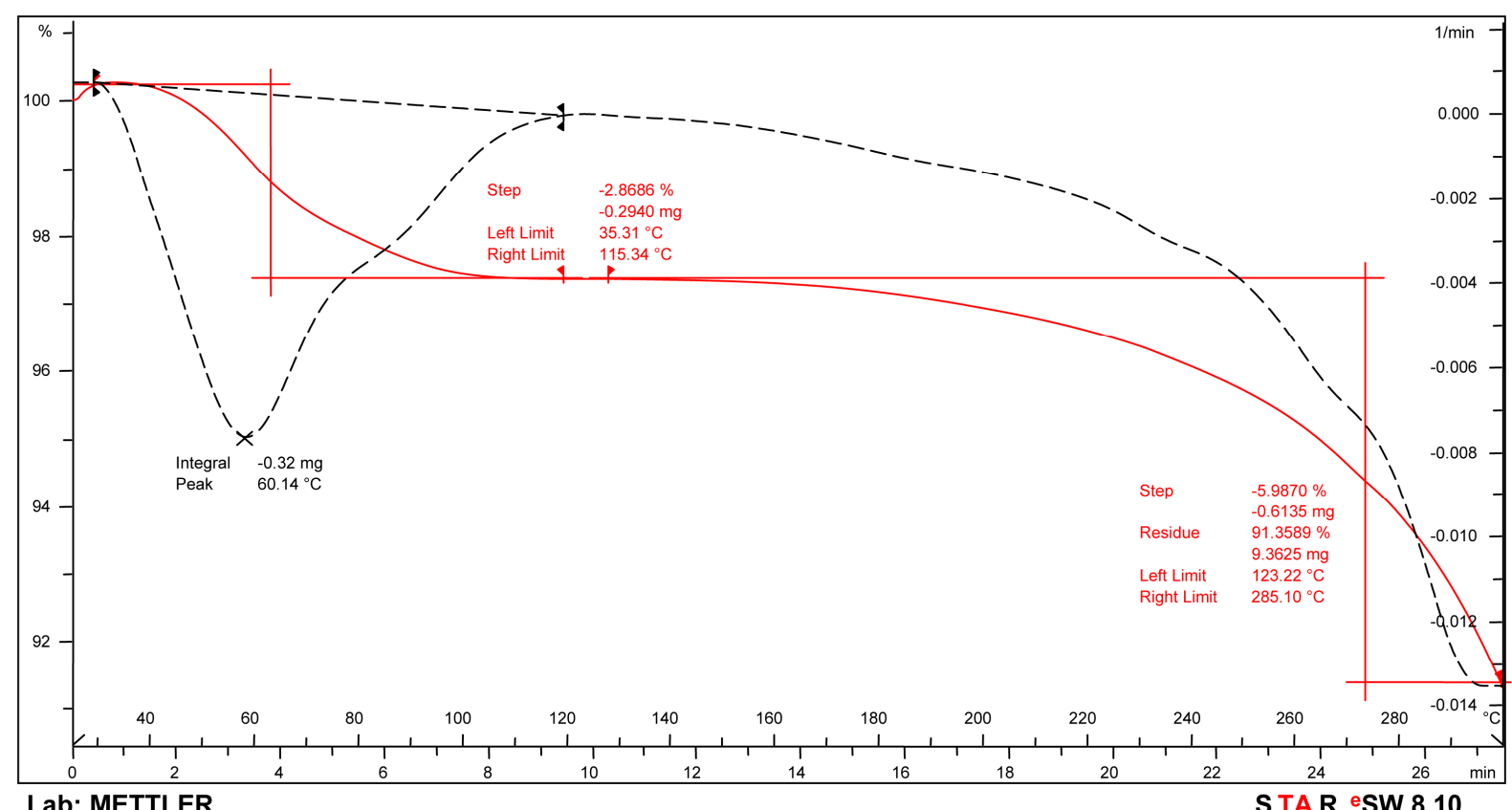

Figure 6. TGA Thermogram of PolyNAM.

Table 6. TGA selected weight loss data.

\begin{tabular}{ccc}
\hline Sample & Weight loss $<\mathbf{1 0 0}^{\circ} \mathbf{C}$ (Peak temperature) & Weight loss $>200^{\circ} \mathbf{C}($ onset to finish temperature) \\
\hline PolyNAM & $2.86 \%\left(60^{\circ} \mathrm{C}\right)$ & $5.98 \%\left(123^{\circ} \mathrm{C}-285^{\circ} \mathrm{C}\right)$ \\
PolyNAS & $1.67 \%\left(64^{\circ} \mathrm{C}\right)$ & $7.11 \%\left(198^{\circ} \mathrm{C}-286^{\circ} \mathrm{C}\right)$ \\
PolyNAA & $1.28 \%\left(56^{\circ} \mathrm{C}\right)$ & $61.22^{\circ}\left(229^{\circ} \mathrm{C}-375^{\circ} \mathrm{C}\right)$ \\
\hline
\end{tabular}


Table 7. Dyeing properties of the dyes on cotton and polyester fabrics.

\begin{tabular}{ccccccc}
\hline \multirow{2}{*}{ Dyed Sample } & \multicolumn{2}{c}{ Light } & \multicolumn{2}{c}{ Washing } & \multicolumn{2}{c}{ Rubbing } \\
\cline { 2 - 7 } & Cotton & Polyester & Cotton & Polyester & Cotton & Polyester \\
\hline PolyNAM & $7-8$ & $6-7$ & 5 & 5 & 5 & 5 \\
PolyNAS & 7 & $6-7$ & 5 & 5 & 5 & 5 \\
PolyNAA & $7-8$ & $6-7$ & 5 & 5 & 5 & 5 \\
\hline
\end{tabular}

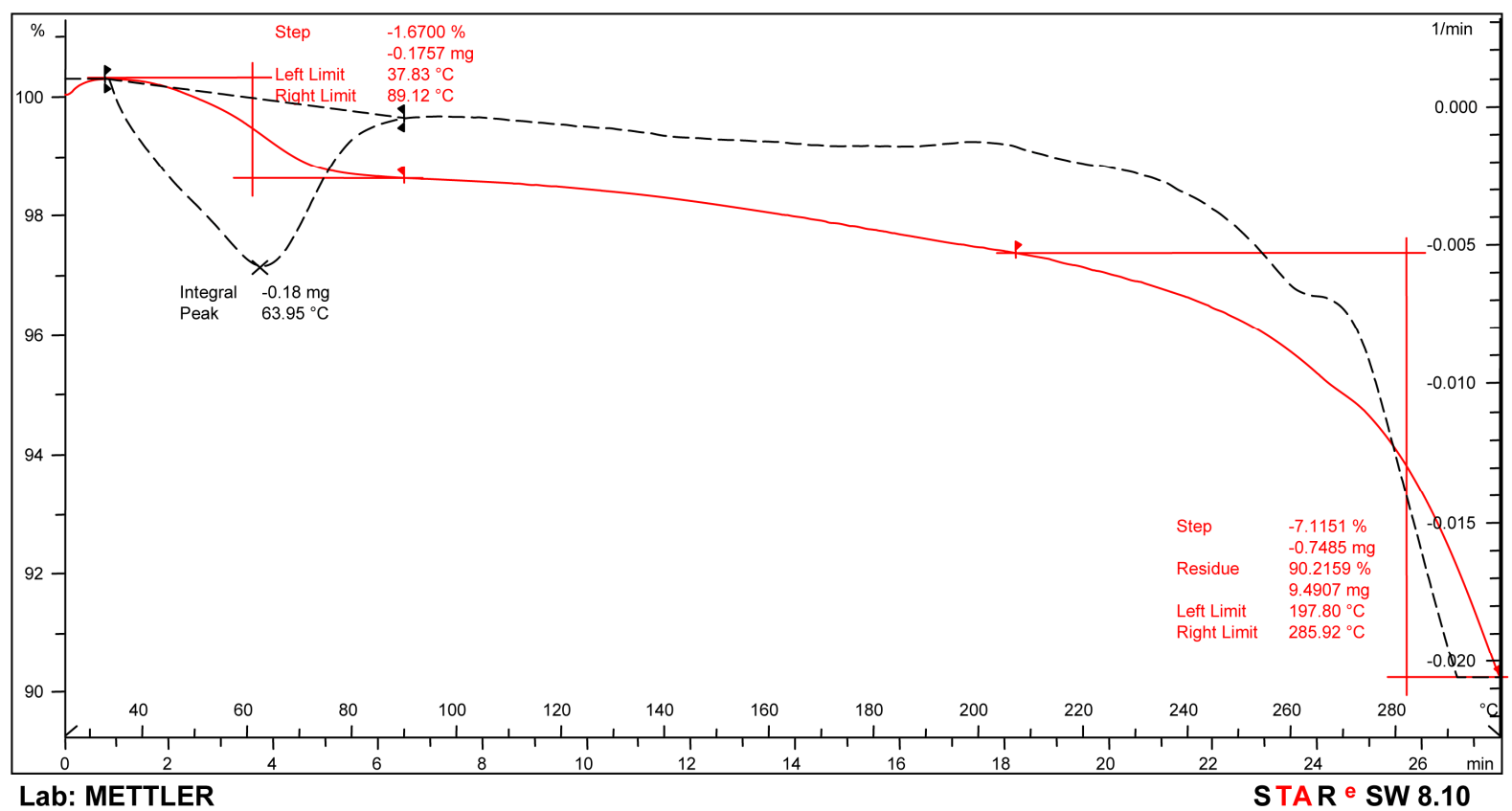

Figure 7. TGA Thermogram of PolyNAS.

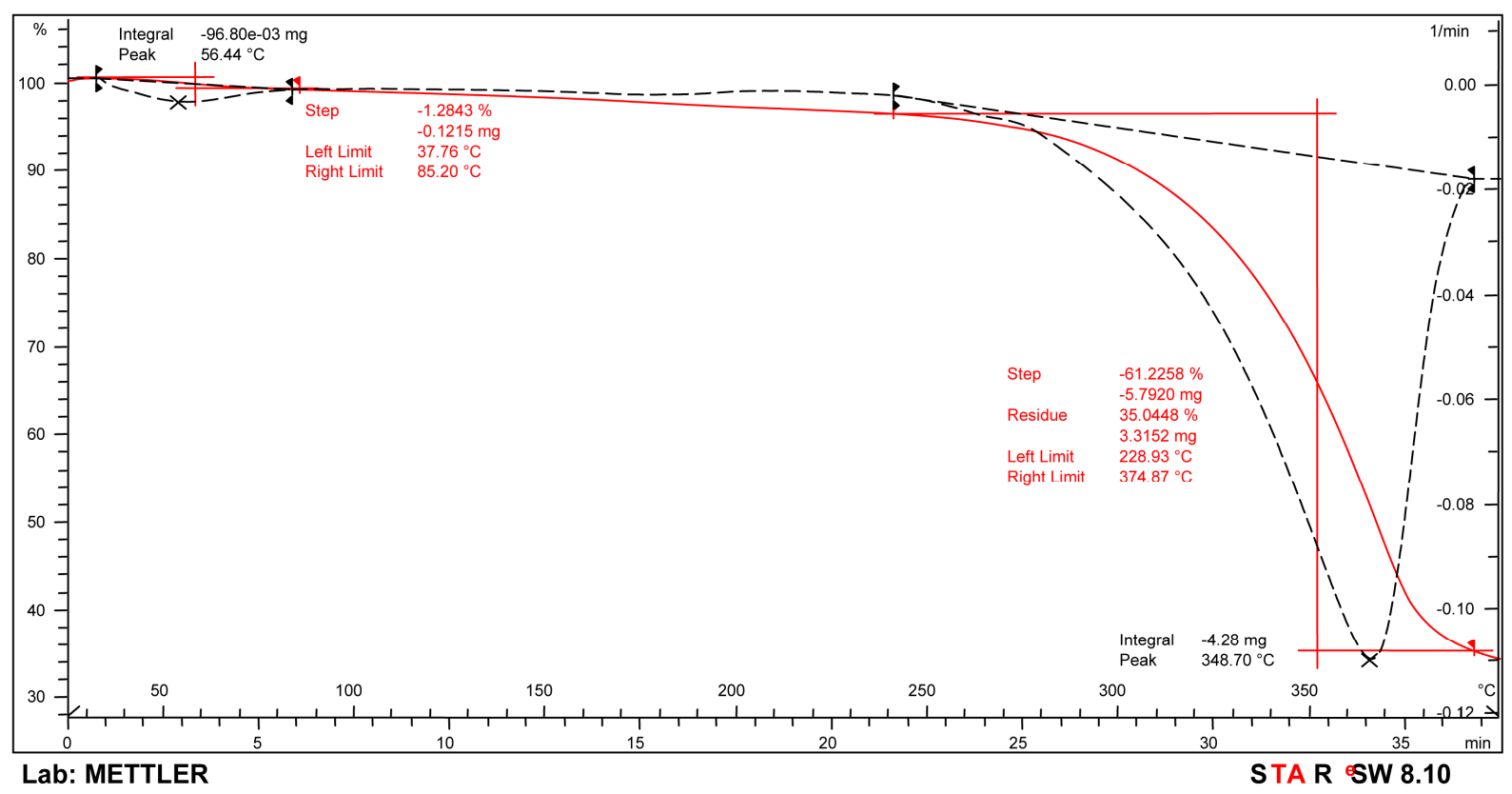

Figure 8. TGA thermogram of PolyNAA. 


\section{Conclusion}

In this work three polymeric dyes containing anthraquinone chromophore were synthesized. The synthesis was achieved using low temperature solution polycondensation technique. Formation of the amide polymeric dyes was confirmed using FT-IR spectroscopy. The products were observed to possess high absorptivity coefficient. Differential Scanning Calorimetry and Thermogravimetry showed that the dyes have good thermal stabilities.

\section{Acknowledgements}

The authors wish to acknowledge the contribution of Dr Abdulsalam A. Salisu and Department of Chemistry, Universiti Putra, Malaysia, for conducting the TGA and DSC analysis and providing the TGA and DSC spectra presented in this write up.

\section{REFERENCES}

[1] J. S. Wang, H. J. Chen and S. Evans, EP 1283249, 2003.

[2] H. R. Maradiya and V. S. Patel, "Studies of Novel Monomeric and Polymeric Azo Disperse Dyes," Journal of Applied Polymer Science, Vol. 84, No. 7, 2002, pp. 13801389. doi:10.1002/app.10276

[3] H. R. Maradiya and V. S. Patel, "N-Arylmaleimide Based Monomeric and Polymeric Dyes for Cellulose Triacetate Fiber," International Journal of Polymeric Materials, Vol. 52, No. 2, 2003, pp. 119-131. doi:10.1080/714975923

[4] X. H. Hu, X. Y. Zhang, J. B. Dai and G. W. Xu, "Synthesis and Characterization of a Novel Aqueous Dispersion Poly[urethane-(disperse blue 14)-urethane] Dye," Chinese Chemical Letters, Vol. 15, No. 5, 2004, pp. 515-517.

[5] K. H. Shah, M. P. Patel, K. G Amin, R. G. Patel and V. S. Patel, "Synthesis and Characterization of Polymeric Dyes," Acta Ciencia Indica Chemistry, Vol. 23, 1997, p. 177.

[6] M. M. Tian, G. R. Hawkins and A. C. Chan, US Patent No. 2003106168, 2003.

[7] L. M. Parrinello, R. Rogers, C. T. Hill, L. E. Lipko, P. L. Benenati and P. Nowakowski, US Patent No. 2003180523, 2003.

[8] I. Grabchev, "Photophysical Characteristics of Polymerizable 1,8-Naphthalimide Dyes and Their Copolymers with Styrene or Methylmethacrylate," Dyes and Pigments, Vol. 38. No. 4, 1998, pp. 219-226. doi:10.1016/S0143-7208(97)00117-4

[9] K. Singh, S. Singh and J. A. Taylor, "Monoazo Disperse Dyes-Part 1: Synthesis, Spectroscopic Studies and Technical Evaluation of Monoazo Disperse Dyes Derived from 2-Aminothiazoles," Dyes and Pigments, Vol. 54, No. 3, 2002, pp. 189-200. doi:10.1016/S0143-7208(02)00053-0

[10] T. Konstantinova, P. Meallier, Hr. Konstantinov and D. Staneva, "Synthesis and Photochemical Properties of Triazinylaminobenzanthrone Derivatives as Dyes for Poly- meric Materials," Polymer Degradation and Stability, Vol. 48, No. 1, 1995, pp. 161-166.

doi:10.1016/0141-3910(95)00014-D

[11] M. Qinghua, H. Deyin, W. Shaohua and C. Lin, "Synthesis and Application of Polymeric Dyes Containing the Anthraquinone Structure," Journal of Applied Polymer Science, Vol. 83, No. 6, 2002, pp. 1252-1257. doi:10.1002/app.2292

[12] K. Sung-Hoon, C. Jian-Zhong, P. Jin-Yong, R. JangHyun, H. S. P. Eun-Mi, J. Sung-Ho, K. Kwangnak and G. Yeong-Soon, "Synthesis and Light Emitting Properties of Polymeric Metal Complex Dyes Based on Hydroxyquinoline Moiety," Dyes and Pigments, Vol. 55, 2002, pp. 91-97. www.elsevier.com/locate/dyepig doi:10.1016/S0143-7208(02)00088-8

[13] J. M. R. C. Fernando and G. K. R. Senadeera, "Synthesis and Characterization of Carboxylated Thiophene CoPolymers and Their Use in Photovoltaic Cells," Current Science, Vol. 95, No. 6, 2008, pp. 743-750.

[14] B. T. Tang, S. F. Zhang, J. Z. Yang and F. Liu, "Synthesis of a Novel Water-Soluble Crosslinking Polymeric Dye with Good Dyeing Properties," Dyes and Pigments, Vol. 68, No. 1, 2006, pp. 69-73.

[15] M. G. Patel, K. R. Desai and H. S. Patel, "Synthesis and Characterization of Colored Polyureas," E-Journal of Chemistry, Vol. 1, No. 1, 2004, pp. 51-56. http://www.e-journals.net

[16] M. Joshi, S. Jauhari and K. R. Desai, "Polyureas: Synthesis and Characterization," International Journal of ChemTech Research CODEN (USA), Vol. 3, No. 1, 2011, pp. 29-32.

[17] J. Park, J. Yang, J. Lee, E. Lim, J. Suh, Y. Huh and S. Haam, "Synthesis and Characterization of Fluorescent Magneto Polymeric Nanoparticles (FMPNs) for Bimodal Imaging Probes," Journal of Colloid and Interface Science, Vol. 340, 2009, pp. 176-181.

doi:10.1016/j.jcis.2009.08.015

[18] H. S. Panah, A. Khosrav, K. Gharanjig, M. Khorassani, M. K. Zadeh and F. A.Taromi, "Synthesis and Characterization of New Fluorescent Polymerizable Dyes Based on Naphthalimide," Iranian Polymer Journal, Vol. 19, No. 7, 2010, pp. 491-500.

[19] M. Edward and M. Caffery, "Laboratory Preparation of Macromolecular Chemistry," Mc Graw-Hill, Inc., New York, 1970, pp. 101-113, 247 and 263.

[20] A. A. Caraculacu, N. C. Lungu and G. Caraculacu, "Aromatic Polyamide with Parabanic Structure," European Polymer Journal, Vol. 24, No. 12, 1988, p. 1207. doi:10.1016/0014-3057(88)90113-9

[21] J. F. Davis, "Synthesis of Aromatic Polyamides, Polymer Chemistry, A practical approach," Oxford University Press, New York, 2004, pp. 126-127.

[22] H. B. William and S. F. Christopher, "Organic Chemistry Text Book," 2nd Edition, Saunders College Publishers, United States, 1998, p. 506.

[23] S. M. Gumel, "Study on the Surface Finishing of Leather Using Some Commercial and Novel Polymers," Ph.D Thesis, Bayero University, Kano, 2001. 
[24] F. W. Billmeyer, "A Text Book of Polymer Science," 2nd Edition, John Wiley and Sons, Inc., New York, 1984, p. 120.

[25] M. Ibrahim, "Synthesis and Characterisation of Polymeric Dyes Derived from 1, 4-Diamino Anthraquinone," Master's Thesis, Bayero University, Kano, 2010.

[26] J. A. Dean, "Lange's Handbook of Chemistry," McGraw Hill Inc., New York, 1992.

[27] T. M. Robert and N. B. Robert, "A Text Book of Organic Chemistry," Prentice Hall of India Private Limited, New Delhi, 2001, pp. 585-596.

[28] J. A. Dean, "The Analytical Chemistry Hand Book," McGraw Hill, Inc., New York, 1995, pp. 15.1-15.5.

[29] K. C. Cole, C. Decker, M. Jutigny, J. M Lefebvre and P. Krawzak, "Biaxial Deformation of Polyamide-6, Assessment of Orientation by Means of IR Trichroism," Poly- mer Engineering and Science, Vol. 44, No. 2, 2000, pp. 231-240.

[30] S. Zhang, Z. Wu and J. Yang, "Polymeric Dyes, A New Field of Dye Chemistry," Dalian University of Technology Press, 1995, Dalian, pp. 45-46.

[31] E. Pungor, "A Practical Guide to Instrumental Analysis," Boca Raton, Florida, 1995, pp. 181-191.

[32] A. S Douglas, F. J. Holler and S. R. Crouch, "Principles of Instrumental Analysis," 5th Edition, Brooks/Cole, Thompson Learning, New York, 1998.

[33] J. Wang, S. Zhang, B. Tang and J. Yang, "Application of Polymeric Dyes in Textile Fields," Proceedings of the 3rd International Conference on Functional Molecules, Dalian, 8-11 September 2005, pp. 8-11. 